\title{
Simulation of boronizing kinetics of ASTM A36 steel with the alternative kinetic model and the integral method
}

\author{
Z. Nait Abdellah ${ }^{1,2}$, M. Keddam², *, P. Jurč $i^{3}$ \\ ${ }^{1}$ Faculté des Sciences, Université Mouloud Mammeri, Algeria \\ ${ }^{2}$ Laboratoire de Technologie des Matériaux, Faculté de Génie Mécanique et Génie des Procédés, Algeria \\ ${ }^{3}$ Faculty of Material Sciences and Technology of the STU in Trnava, Slovakia \\ E-mail: keddam@yahoo.fr
}

In this study, two different mathematical models have been proposed for estimating the diffusivities of boron in the $\mathrm{Fe}_{2} \mathrm{~B}$ layer on ASTM A36 steel in the range of 1173 to $1273 \mathrm{~K}$ with exposure times of 2 to $8 \mathrm{~h}$. The boride incubation period required for the formation of such a layer was constant regardless of the boriding conditions. In both approaches, the boron diffusivity in the iron phase was considered in an unsaturated matrix. The first approach was derived from the mass balance equation at the $\left(\mathrm{Fe}_{2} \mathrm{~B} /\right.$ substrate $)$ interface while the second approach employed the integral diffusion model. The calculated values of boron activation energies for ASTM A36 steel were found to be very comparable for the two approaches (161.65 and 160.96 and $\mathrm{kJ} \mathrm{mol}^{-1}$ ). Afterwards, these values of activation energy were confronted with the results from the literature. Experimental validation of these two approaches has been done by comparing the experimental value of $\mathrm{Fe}_{2} \mathrm{~B}$ layer thickness measured at $1123 \mathrm{~K}$ for $2.5 \mathrm{~h}$ with the simulated values. Finally, the predicted values of $\mathrm{Fe}_{2} \mathrm{~B}$ layer thickness were in line with the experimental measurement.

\section{INTRODUCTION}

The boriding treatment is a thermochemical process based on the diffusion phenomenon of atomic boron from a boron-rich source at temperatures in the range $800-1050{ }^{\circ} \mathrm{C}$ and for durations from 0.5 to $10 \mathrm{~h}$. This surface treatment provides interesting surface properties for the parts to be treated. A high hardness related to the wear resistance is obtained at the surface of ferrous alloys owing to the formation of hard boride layers [1]. In the literature, different boriding processes can be conducted depending upon the physical state of active components: gas $[2,3]$, liquid $[4,5]$, paste $[6,7]$, powder [8-10], fluidized bed [11], plasma-electrolytic [12], plasma-assisted [13], and plasma-paste [14].
In practice, the most commonly employed process is the powder-pack boriding due to its technical simplicity and cost-effectiveness, as compared with other boriding processes [15]. From a kinetic point of view, different approaches have been proposed to deal with the growth kinetics of boride layers at the surfaces of Armco iron and steels $[6,7,8,16-25]$. All these approaches serve as useful tools for selecting the optimum values of boride layers' thicknesses according to the requirements imposed by the end-users in the industry. As an indication, Zuno-Silva et al.[18] have used the integral method for studying the boriding kinetics of AISI 1045 steel in the range of 1123 to $1273 \mathrm{~K}$ by ignoring the boron diffusivity in the iron phase in a saturated substrate. Campos-Silva et al. [7] have proposed a modified formulation of the mass balance equation at the $\left(\mathrm{Fe}_{2} \mathrm{~B} /\right.$ substrate $)$ interface for the $\mathrm{Fe}_{2} \mathrm{~B}$ layers on AISI 1018 steel within a saturated matrix with the occurrence of boride incubation periods. In their diffusion model, the boron diffusivity in the iron phase (either $\alpha$-Fe or $\gamma$-Fe) was neglected. Recently, Keddam and Jurči [23] have suggested an alternative diffusion model which was applied to the pack-boriding of AISI 316 steel within a saturated matrix with boron atoms. In the present work, the same model was adopted for studying the growth of $\mathrm{Fe}_{2} \mathrm{~B}$ layers on ASTM A36 steel by considering a non saturated substrate with boron atoms and the boron diffusivity in the iron phase.

The aim of the present work is to study the kinetics of boride layers on ASTM A36 steel, by using two mathematical approaches (an alternative kinetic model and the integral method) for a constant boride incubation period. The boron diffusivity in the iron phase and its solubility within the matrix were taken into account in both approaches. Finally, these two models have been checked experimentally by considering an additional boriding condition (at a temperature of $1123 \mathrm{~K}$ for $2.5 \mathrm{~h}$ ). 


\section{DIFFUSION MODELS}

\section{The alternative diffusion model}

This first approach is starting from the balance equation at the $\left(\mathrm{Fe}_{2} \mathrm{~B} /\right.$ substrate $)$ interface by considering the boron diffusivity in the iron phase (either $\alpha$-Fe or $\gamma-\mathrm{Fe})$. Figure 1 depicts a schematic boron concentrationprofile inside the $\mathrm{Fe}_{2} \mathrm{~B}$ layer. $\mathrm{C}_{u p}^{\mathrm{Fe}}{ }_{2} \mathrm{~B}$ and $\mathrm{C}_{\mathrm{low}}^{\mathrm{Fe}} \mathrm{e}^{\mathrm{B}}$ are the maximum and minimum boron contents in the $\mathrm{Fe}_{2} \mathrm{~B}$ layer, respectively. The $\mathrm{Fe}_{2} \mathrm{~B}$ layer thickness is designated by the variable $x(t)=\mathrm{u} . C_{a d s}$ is relative to the adsorbed boron concentration at the surface of the material [26]. $C_{B}^{F e}$ (in wt.\%) is the boron solubility within the iron substrate calculated from the interstitial model based on the Calphad formalism [27]. According to the iron-boron system [28 ], two iron borides exist $\left(\mathrm{FeB}\right.$ and $\left.\mathrm{Fe}_{2} \mathrm{~B}\right)$ at equilibrium condition. The first iron boride being formed is $\mathrm{Fe}_{2} \mathrm{~B}$ for a treatment time exceeding the boride incubation period. After saturating the matrix (iron) with boron atoms, the first nuclei of boride crystals begin to appear and afterwards they transform into boride needles by growth with preferred crystallographic orientations and texture [29]. When the boride needles come into contact, the surface is being covered by a compact $\mathrm{Fe}_{2} \mathrm{~B}$ layer when surpassing the boride incubation period. In practice, it is possible to generate the $\mathrm{Fe}_{2} \mathrm{~B}$ layer instead of the dual phase boride layer $\left(\mathrm{FeB}+\mathrm{Fe}_{2} \mathrm{~B}\right)$ by using adequate chemical compositions of powders mixture during the pack-boriding process. In the majority of published works in the literature, commercial agents such as Ekabor and Durborid are widely used in the boronizing of steels [1]. In these circumstances, a bilayer composed of $\mathrm{FeB}$ and $\mathrm{Fe}_{2} \mathrm{~B}$ layers is being formed for almost all boriding conditions. For instance in the reference [30], the powders mixture used for generating a single boride layer $\left(\mathrm{Fe}_{2} \mathrm{~B}\right)$ was composed of $20 \% \mathrm{~B}_{4} \mathrm{C}$, $10 \% \mathrm{KBF}_{4}$ and $70 \% \mathrm{SiC}$ (given in weight percent). In other studies, Turkmen et al. [31, 32] have employed

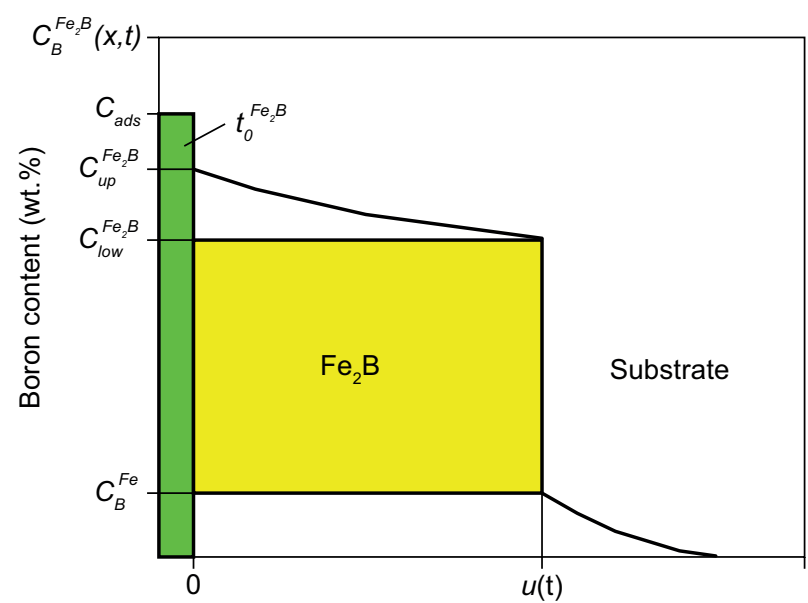

Fig. 1. Schematic boron-concentration profile inside the $\mathrm{Fe}_{2} \mathrm{~B}$ layer in an unsaturated matrix two alternative boron sources (acid boric $\mathrm{H}_{3} \mathrm{BO}_{3}$ and disodium octaborate $\mathrm{Na}_{2} \mathrm{~B}_{8} \mathrm{O}_{13}$ ) for the pack-boronizing of SAE 1020 steel. Particularly, in the reference work [31], the chemical composition of the powders mixture used to get the formation of $\mathrm{Fe}_{2} \mathrm{~B}$ layer was composed of 22.5 wt. $\% \mathrm{H}_{3} \mathrm{BO}_{3}, 5$ wt. $\% \mathrm{KBF}_{4}$ and 27.2 wt. $\% \mathrm{SiC}$.

The phase composition of boride layers can also be influenced by the treatment time and the boriding temperature. In this respect, Gunen et al.[ 33] have employed the pack-boriding treatment for AISI H13 steel with another powders mixture containing 95 wt. $\% \mathrm{~B}_{4} \mathrm{C}$ and 5 wt. $\% \mathrm{NaBF}_{4}$ between 800 and $1000{ }^{\circ} \mathrm{C}$. As a result, the $\mathrm{Fe}_{2} \mathrm{~B}$ layer was only obtained at $800{ }^{\circ} \mathrm{C}$ while a double-phase boride layer $\left(\mathrm{FeB}+\mathrm{Fe}_{2} \mathrm{~B}\right)$ was formed at 900 and $1000^{\circ} \mathrm{C}$.

In the alternative diffusion model, the incremental change in the boron concentration $d C_{\mathrm{Fe}_{2} B}(\mathrm{x}, \mathrm{t})$ inside the $\mathrm{Fe}_{2} \mathrm{~B}$ layer, with the treatment time $\mathrm{t}$ and diffusion distance $x$, is expressed by Equation (1) for the given boriding temperature [23]:

$$
d C_{\mathrm{Fe}_{2} B}(x, t)=\frac{\partial C_{\mathrm{Fe}_{2} B}(x, t)}{\partial t} d t+\frac{\partial C_{\mathrm{Fe}_{2} B}(x, t)}{\partial x} d x
$$

with $\frac{\partial C_{\mathrm{Fe}_{2} B}(x, t)}{\partial x}=\frac{1}{2} \frac{d C_{\mathrm{Fe}_{2} B}(x, t)}{d t} \frac{d t}{d x}$

The time dependence of $\mathrm{Fe}_{2} \mathrm{~B}$ layer thickness is given by Equation (2):

$$
u=k \sqrt{t-t_{0}^{F e_{2} B}}
$$

where $u(t)$ is the $\mathrm{Fe}_{2} \mathrm{~B}$ layer thickness (in $\mu \mathrm{m}$ ) and $k$ the corresponding parabolic growth constant (in $\mu \mathrm{m} \mathrm{s}^{-0.5}$ ). Equation (2) is mathematically similar to Equation (3):

$$
u=k^{\prime} \sqrt{t}
$$

where the constant $k^{\prime}$ represents the new value of parabolic growth constant at the $\left(\mathrm{Fe}_{2} \mathrm{~B} /\right.$ substrate $)$ interface corresponding to the fictitious zero incubation time. The boron distribution within the iron phase is described by Equation (4) derived from the Second Fick's law:

$$
C_{B}(x, t)=\frac{C_{B}^{F e}}{\operatorname{erfc}\left(\frac{u}{2 \sqrt{D_{B}^{F e} t}}\right)} \operatorname{erfc}\left(\frac{x}{2 \sqrt{D_{B}^{F e} t}}\right)
$$

The diffusion coefficient of boron in the iron phase (in $\left.\mathrm{m}^{2} \mathrm{~s}^{-1}\right)$ with two allotropic forms $(\alpha-\mathrm{Fe}$ and $\gamma-\mathrm{Fe})$ was given in the reference [34].

$$
\begin{gathered}
D_{B}^{F e}=8.3 \times 10^{-9} \exp \left(-\frac{62700}{R T}\right) \text { for } T<1184.6 \mathrm{~K} \\
D_{B}^{F e}=4.4 \times 10^{-8} \exp \left(-\frac{81500}{R T}\right) \\
\text { for } 1184.6 \leq T \leq 1273
\end{gathered}
$$

with $R=8.314 \mathrm{Jmol}^{-1} \mathrm{~K}^{-1}$ and $T$ the temperature in Kelvin. 
In this case, the mass balance equation at the $\left(\mathrm{Fe}_{2} \mathrm{~B} /\right.$ substrate) interface (located at $x=u$ ) can be re-written as follows:

$$
\left.w \frac{d x}{d t}\right|_{x=u}=-\left.\frac{1}{2} D_{\mathrm{Fe}_{2} B} \frac{d C_{\mathrm{Fe}_{2} B}}{d t} \frac{d t}{d x}\right|_{x=u}-\left.J_{B}^{F e}\right|_{x=u}
$$

with $\left.J_{B}^{F e}\right|_{x=u}=C_{B}^{F e} \sqrt{\frac{D_{B}^{F e}}{\pi t}}$

Equation (7) can also take the following form by multiplying each side of it by the term of velocity $\left.(d x / d t)\right|_{x=u}$ at the considered interface:

$$
w\left(\left.\frac{d x}{d t}\right|_{x=u}\right)^{2}=-\frac{1}{2} D_{\mathrm{Fe}_{2} B} \frac{d C_{\mathrm{Fe}_{2} B}}{d t}-\left.\left.J_{B}^{F e}\right|_{x=u} \frac{d x}{d t}\right|_{x=u}
$$

Finally, Equation (8) can be re-written as follows:

$$
w\left(\left.\frac{d x}{d t}\right|_{x=u}\right)^{2} d t=-\frac{1}{2} D_{F_{2} B} d C_{F_{2} B}-\left.C_{B}^{F e} \sqrt{\frac{D_{B}^{F e}}{\pi t}} \frac{d x}{d t}\right|_{x=u} d t
$$

The $\Phi$ parameter can be introduced in order to include the effect of incubation period when forming the $\mathrm{Fe}_{2} \mathrm{~B}$ layer at the surface of the material as follows:

$$
\Phi=\sqrt{1-\frac{t_{0}^{F e_{2} B}}{t}}=\frac{k^{\prime}}{k}
$$

Equation (9) can be re-written in the integral form as follows:

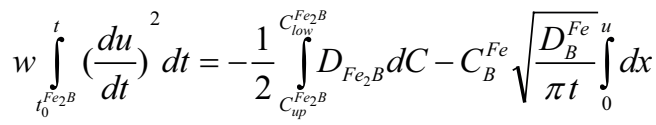

By integrating each term of this last equation and substitution of Equation (3) and its derivative with respect to the time, we get Equation (12) which is used to assess the diffusion coefficient of boron in $\mathrm{Fe}_{2} \mathrm{~B}$ :

$$
D_{\mathrm{Fe}_{2} B}=\frac{\left[w k^{\prime 2} \ln \left[\frac{1}{\left(1-\Phi^{2}\right)}\right]+4 C_{B}^{F e} \sqrt{\frac{D_{B}^{F e}}{\pi}} k^{\prime}\right]}{2\left(C_{u p}^{F_{2} B}-C_{l o w}^{F e_{2} B}\right)}
$$

Equation (12) is a generalized form compared to that found by Campos-Silva et al.[16] since the boron diffusivity in the iron phase was taken into account in an unsaturated matrix. For the estimation of $\mathrm{Fe}_{2} \mathrm{~B}$ layer thickness by the alternative diffusion model, Equation (13) can be used for a given process temperature at the incubation period $t_{0}^{\mathrm{Fe}_{2} \mathrm{~B}}$ :

$$
u=\frac{\left[-2 C_{B}^{F e} \sqrt{\frac{D_{B}^{F e}}{\pi}}+\sqrt{4 \frac{D_{B}^{F e}}{\pi}\left(C_{B}^{F e}\right)^{2}+2 w \ln \left(\frac{1}{1-\Phi^{2}}\right) D_{F_{2} B}\left(C_{u p}^{F e_{2} B}-C_{l o w}^{F e_{0} B}\right)}\right]}{w \Phi \ln \left(\frac{1}{1-\Phi^{2}}\right)}
$$

$$
\sqrt{t-t_{0}^{F e_{2} B}}
$$

\section{The integral diffusion model}

The integral diffusion model [35] is proposed as a second approach to analyze the boriding kinetics of ASTM A36 steel. This kinetic approach was recently used to simulate the kinetics of $\gamma$ ' layers grown on pure iron that has been plasma nitrided in a microwave discharge chamber. It deals with the growth kinetics of $\mathrm{Fe}_{2} \mathrm{~B}$ layers over an unsaturated matrix. The initial and boundary conditions for this model are established as follows:

$$
\begin{aligned}
& \text { For } t=0, x>0 \text {, with } C_{B}(x, t=0)=0 \text { wt. } \% \\
& C_{B}^{F e_{2} B}\left(x\left(t=t_{0}^{F e_{2} B}\right)=0, t=t_{0}^{F e_{2} B}\right)=C_{u p}^{F e_{2} B} \\
& \text { for } C_{a d s}>8.83 \text { wt. } \% \\
& C_{B}^{F e_{2} B}(x(t=t)=u, t=t)=C_{l o w}^{F e_{2} B} \\
& \text { for } C_{a d s}>8.83 \text { wt. } \%
\end{aligned}
$$

Based on the Goodman's method [36], the expression of boron distribution inside the $\mathrm{Fe}_{2} \mathrm{~B}$ layer is provided by Equation (17):

$$
\begin{aligned}
& C_{B}^{F e_{2} B}(x, t)=C_{l o w}^{F e_{2} B}+a(t)[u(t)-x]+b(t)[u(t)-x]^{2} \\
& \quad \text { for } 0 \leq x \leq u
\end{aligned}
$$

where $a(t), b(t)$ and $u(t)$ must fulfil the boundary conditions provided by Equations (15) and (16). The solution of this diffusion model is given by the following system of differential algebraic equations (DAE) once the diffusion coefficient of boron in the $\mathrm{Fe}_{2} \mathrm{~B}$ phase is determined at a given boriding temperature:

$$
a(t) u(t)+b(t) u(t)^{2}=\left(C_{u p}^{F e_{2} B}-C_{u p}^{F e_{2} B}\right)
$$

$$
\left[a(t)^{2}-2 w b(t)\right] D_{F_{2} B}=a(t) \frac{C_{B}^{F e}}{\operatorname{erfc}\left(\frac{u}{2 \sqrt{D_{B}^{F e}}}\right)} \sqrt{\frac{D_{B}^{F e}}{\pi t}} e^{-\frac{u^{2}}{4 D_{B}^{F e} t}}
$$

$$
\frac{d}{d t}\left[\frac{u(t)^{2}}{2} a(t)+\frac{u(t)^{3}}{3} b(t)\right]=2 D_{\mathrm{Fe}_{2} B} b(t) u(t)
$$

with $w=\frac{\left(C_{u p}^{F e_{2} B}+C_{B}^{F e_{2} B}-2 C_{B}^{F e}\right)}{2}$

The unknowns of this DAE system are $a(t), b(t)$ and $u(t)$. For estimating the diffusion coefficients of boron in the $\mathrm{Fe}_{2} \mathrm{~B}$ phase, the following changes of variable were considered:

$$
u=2 \varepsilon \sqrt{D_{\mathrm{Fe}_{2} B} t}
$$

where $u(t)$ is the $\mathrm{Fe}_{2} \mathrm{~B}$ layer thickness (in $\mu \mathrm{m}$ ), $\varepsilon$ a non dimensional parameter and $k^{\prime}=2 \varepsilon \sqrt{D_{F e 2 B}}$ the corresponding parabolic growth constant (in $\mu \mathrm{m} \mathrm{s}^{-0.5}$ ) or the slope of the straight line giving the layer thickness versus the square root of time. 
and

$$
a(t)=\frac{\alpha}{u(t)}
$$

$$
b(t)=\frac{\beta}{u(t)^{2}}
$$

where the constants $\alpha, \beta$ and $\varepsilon$ are defined positive. By substituting Equations (22) and (23) into Equation (18), Equation (24) was derived :

$$
\alpha+\beta=\left(C_{u p}^{\mathrm{Fe}_{2} B}-C_{u p}^{\mathrm{Fe}_{2} B}\right)
$$

The $\varepsilon$ parameter depends on the both constants $\alpha$ and $\beta$ and its expression is given by Equation (25):

$$
\varepsilon=\sqrt{\frac{\beta}{\left(\frac{\alpha}{2}+\frac{\beta}{3}\right)}}
$$

Equation (25) was deduced through a derivation of Equations (22), (23) and (3) with respect to the time $t$ and after substitution into Equation (20). Equation (26) was obtained after substituting Equations (21), (22) and (23) into Equation (19) and by considering Equation (25):

$$
\left(\alpha^{2}-2 w \beta\right) k^{\prime}=4 \alpha \varepsilon^{2} \frac{C_{B}^{F e}}{\operatorname{erfc}\left(\frac{k^{\prime}}{2 \sqrt{D_{B}^{F e}}}\right)} \sqrt{\frac{D_{B}^{F e}}{\pi}} e^{-\frac{k^{\prime 2}}{4 D_{B}^{F e}}}
$$

valid for $\alpha^{2}>2 \mathrm{w} \beta$

The solutions of the non linear equations (24) and (26) yield the numerical values of $\alpha$ and $\beta$ by utilizing the Newton-Raphson numerical routine [37]. Therefore, the value of boron diffusion coefficient in $\mathrm{Fe}_{2} \mathrm{~B}$ can be easily deduced from Equation (27) for the corresponding value of parabolic growth constant $k$.

$$
D_{\mathrm{Fe}_{2} B}=\eta k^{\prime 2}
$$

with $\eta=1 / 4 \varepsilon^{2}$

For the integral method, the $\mathrm{Fe}_{2} \mathrm{~B}$ layer thickness can be expressed by Equation (28):

$$
u=\frac{1}{\Phi} \sqrt{\frac{D_{F_{2} B}}{\eta}\left(t-t_{0}^{F e_{2} B}\right)}
$$

\section{RESULTS AND DISCUSSIONS}

The experimental data obtained by Ortiz-Dominguez et al.[25] were used to assess the values of boron activation energies in ASTM A36 steel. Afterwards, the two suggested kinetics approaches have been checked experimentally by considering an extra boriding condition. The ASTM A36 steel had the following chemical composition (in weight percent): $0.25-0.29 \% \mathrm{C}$, $0.20-0.28 \% \mathrm{Si}, 0.85-1.35 \% \mathrm{Mn}, 0.15-0.20 \% \mathrm{Cu}$, $0.035-0.040 \% \mathrm{P}$ and $0.050 \% \mathrm{~S}$. In the cited investiga- tions [25], the powder pack-boriding was employed to produce the monolayer $\left(\mathrm{Fe}_{2} \mathrm{~B}\right)$ on the surface of ASTM A36 steel. The processes were carried out in the temperature range 1123-1273 K and, for durations from 2 to $8 \mathrm{~h}$. The boron source used during the boriding experiments was Ekabor II whose chemical composition was not given. Furthermore, the SEM observations of the cross-sections of borided samples revealed the presence of $\mathrm{Fe}_{2} \mathrm{~B}$ layer, this result was verified by XRD analysis [25].

Table 1 lists the experimentally determined values of parabolic growth constants at the $\left(\mathrm{Fe}_{2} \mathrm{~B} /\right.$ substrate $)$ interface together with the boride incubation periods. The obtained values of parabolic growth constants are the slopes of the straight lines fitted with Equation (2) and the boride incubation times represent the intercepts with an abscissa axis for a null layer thickness. In order to asses the value of $\Phi$ parameter, it is necessary to determine the new parabolic growth constants at the $\left(\mathrm{Fe}_{2} \mathrm{~B} /\right.$ substrate) interface fitted with Equation (3).

Tab. 1. Experimental parabolic growth constants of the $\mathrm{Fe}_{2} \mathrm{~B}$ phase fitted by Equation (2) with the associated values of boride incubation periods

\begin{tabular}{|c|c|c|}
\hline $\begin{array}{c}\text { Temperature } \\
(\mathbf{K})\end{array}$ & $\begin{array}{c}\mathbf{k} \\
\left(\boldsymbol{\mu} \mathbf{m ~ s}^{-0.5}\right)\end{array}$ & $\begin{array}{c}\text { Incubation period } \\
(\mathbf{s})\end{array}$ \\
\hline 1123 & 0.5300 & 1800.7 \\
\hline 1173 & 0.7822 & 1792.6 \\
\hline 1223 & 1.1312 & 1791.3 \\
\hline 1273 & 1.4453 & 1790.3 \\
\hline
\end{tabular}

Table 2 gives the new values of parabolic growth constants fitted with Equation (3) and the corresponding value of $\Phi$ parameter is unchanged whatever the boriding temperature because the boride incubation period is nearly constant. Before estimating the values of activation energies for boron diffusion by using the two approaches. It is necessary to firstly determine the values of boron diffusion coefficients in $\mathrm{Fe}_{2} \mathrm{~B}$.

Tab. 2. New values of parabolic growth constants fitted with Equation (3) and the determination of parameter

\begin{tabular}{|c|c|c|}
\hline $\begin{array}{c}\text { Temperature } \\
(\mathbf{K})\end{array}$ & $\begin{array}{c}\mathbf{k} \\
\left(\boldsymbol{\mu} \mathbf{m ~ s}^{-\mathbf{0 . 5}}\right)\end{array}$ & The $\boldsymbol{\Phi}$ parameter \\
\hline 1123 & 0.5026 & 0.9483 \\
\hline 1173 & 0.7419 & 0.9484 \\
\hline 1223 & 1.0729 & 0.9484 \\
\hline 1273 & 1.3708 & 0.9484 \\
\hline
\end{tabular}

Figure 2 gives the natural logarithm of calculated boron diffusion coefficients in $\mathrm{Fe}_{2} \mathrm{~B}$ by the alternative diffusion model versus the reciprocal temperature. 
Equation (29) represents the results of data fitting with the Arrhenius relation:

$$
D_{\mathrm{Fe}_{2} B}=5.13 \times 10^{-4} \exp \left(-\frac{161.65 \mathrm{~kJ}}{R T}\right)
$$

with $R=8.314 \mathrm{~J} \mathrm{~mol}^{-1} \mathrm{~K}^{-1}$ and $T$ the temperature in Kelvin.

The value of boron activation energy in ASTM A36 steel $\left(=161.65 \mathrm{~kJ} \mathrm{~mol}^{-1}\right)$ was easily found from the slope of the straight line shown in Figure 2.

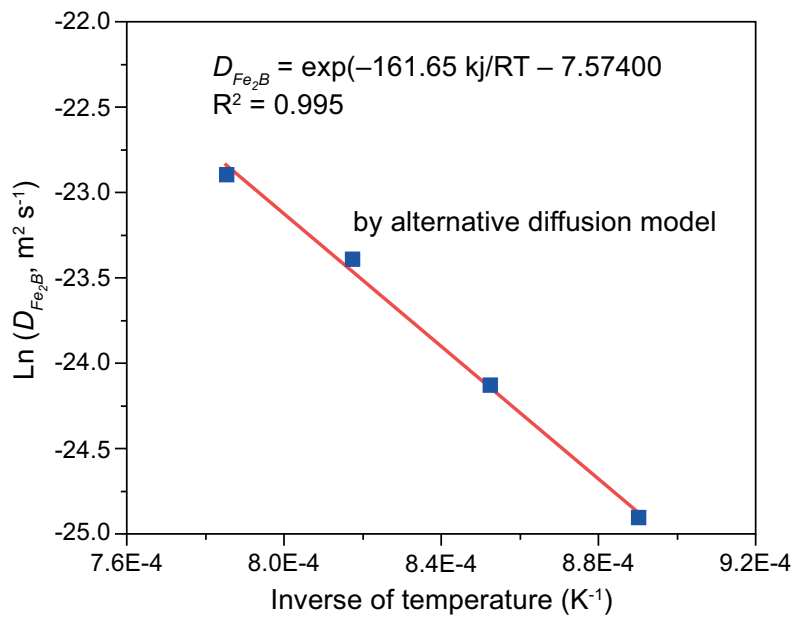

Fig. 2. Arrhenius relationship between the calculated boron diffusion coefficients in $\mathrm{Fe}_{2} \mathrm{~B}$ and the process temperature using the alternative diffusion model

Figure 3 shows the temperature dependence of boron diffusion coefficients in $\mathrm{Fe}_{2} \mathrm{~B}$. The diffusion coefficients calculated by the integral diffusion model are fitted with the Arrhenius relation given by Equation (30):

$$
D_{\mathrm{Fe}_{2} \mathrm{~B}}=1.06 \times 10^{-4} \exp \left(-\frac{160.96 \mathrm{~kJ}}{R T}\right)
$$

with $R=8.314 \mathrm{~J} \mathrm{~mol}^{-1} \mathrm{~K}^{-1}$ and $T$ the temperature in Kelvin.
From the slope of the straight line plotted in Figure 3, the value of boron activation energy for boron diffusion in ASTM A36 steel can be deduced as equal to $160.96 \mathrm{~kJ} \mathrm{~mol}^{-1}$.

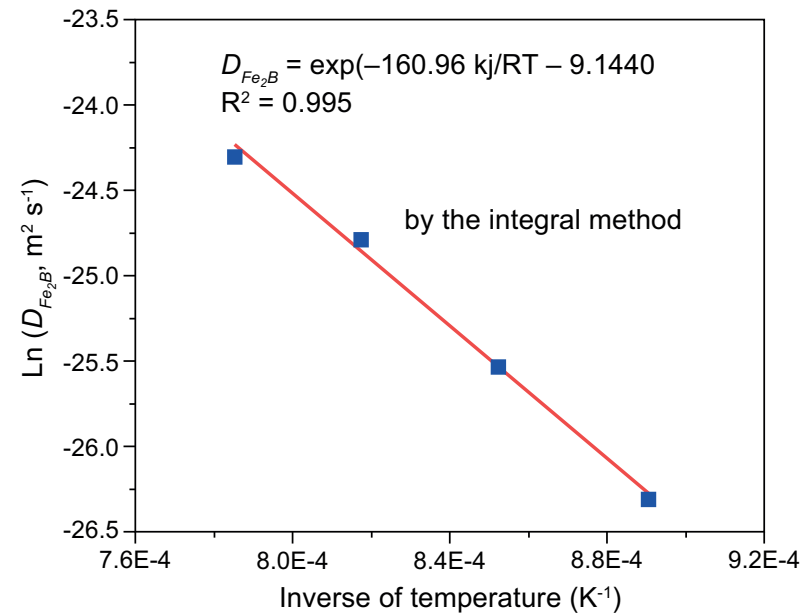

Fig. 3. Arrhenius relationship between the calculated boron diffusion coefficients in $\mathrm{Fe}_{2} \mathrm{~B}$ and the process temperature using the integral method

The reported values of boron activation energies for some borided steels $[6-10,25]$ together with the results found for ASTM A36 steel (present study) are summarized in Table 3. It is worth noting that these values of boron activation energies found in the literature are a function of the following variables: the boriding method (powder or paste), the calculation method, the temperatures range, and the chemical composition of steels to be thermochemically treated. For instance, the AISI 51000 bearing steel containing about $1.00 \mathrm{wt} . \%$ of carbon and a similar chromium content was pack-borided using Ekabor II powder between 1123 and $1223 \mathrm{~K}$ for 2 to $8 \mathrm{~h}$ [9]. The formed boride layer had an acicular shape, and constituted of $\mathrm{Fe}_{2} \mathrm{~B}$ as a major phase, and of a small amount of chromium boride $\left(\mathrm{Cr}_{2} \mathrm{~B}\right)$ precipitates.

Tab. 3. Comparison of boron activation energies for ASTM A36 steel with those of treated materials with solid boriding

\begin{tabular}{|c|c|c|c|c|c|}
\hline Material & $\begin{array}{c}\text { Boriding } \\
\text { method }\end{array}$ & $\begin{array}{c}\text { Temperature } \\
\text { range (K) }\end{array}$ & $\begin{array}{c}\text { Boron activation energy } \\
\left(\mathbf{k J ~ m o l}^{-1}\right)\end{array}$ & Calculation method & Refs. \\
\hline Armco iron & Paste & $1123-1273$ & $151.0\left(\mathrm{Fe}_{2} \mathrm{~B}\right)$ & Diffusion model & {$[6]$} \\
\hline AISI 1080 Steel & Paste & $1123-1273$ & $167.0\left(\mathrm{Fe}_{2} \mathrm{~B}\right)$ & Diffusion model & {$[7]$} \\
\hline Armco iron & Powder & $1123-1273$ & $157.94\left(\mathrm{Fe}_{2} \mathrm{~B}\right)$ & $\begin{array}{c}\text { Mean diffusion } \\
\text { coefficient method }\end{array}$ & {$[8]$} \\
\hline AISI 51100 Steel & Powder & $1123-1223$ & $106.0\left(\mathrm{Fe}_{2} \mathrm{~B}\right)$ & Parabolic growth law & {$[9]$} \\
\hline AISI P20 Steel & Powder & $1123-1223$ & $\begin{array}{c}\left(\mathrm{FeB}+\mathrm{Fe}_{2} \mathrm{~B}\right) 256.4(\text { in conventional furnace) } \\
\text { and } 213.935(\text { in microwave furnace })\end{array}$ & Parabolic growth law & {$[10]$} \\
\hline ASTM A36 Steel & Powder & $1123-1273$ & $160.99\left(\mathrm{Fe}_{2} \mathrm{~B}\right)$ & Diffusion model & {$[25]$} \\
\hline ASTM A36 Steel & Powder & $1123-1273$ & $\begin{array}{c}161.65\left(\mathrm{Fe}_{2} \mathrm{~B}\right) \text { by the alternative diffusion } \\
\text { model }\end{array}$ & $\begin{array}{c}\text { Alternative diffusion } \\
\text { model and integral } \\
\text { method }\end{array}$ & $\begin{array}{c}\text { Present } \\
\text { work }\end{array}$ \\
\hline
\end{tabular}


The calculated boron activation energy for this steel was $106 \mathrm{~kJ} \mathrm{~mol}^{-1}$, i.e. much lower that what was obtained for the $\mathrm{Fe}_{2} \mathrm{~B}$ layers grown on the Armco iron surface [6, 8]. It is known that the boron activation energy should be increased with the increase of the alloying elements content in the steels. Therefore, the obtained boron activation energy value is inconsistent with the literature data. The determined boron activation energy for AISI 51100 steel contradicted the results of other finding, e.g., [38]. Kayali [10] has pack-borided the AISI P20 steel using Ekabor II powder in the temperature range 1123-1223 K, for durations 2-6 h, and under two types of heating in the furnace.

The calculated boron activation energy was lower in the case of micro-wave heating as compared with the conventional heating in the furnace. Furthermore, it is noticed that the calculated values of boron activation energies in ASTM A36 steel were very comparable for the alternative diffusion model and the integral method. These values of energy were required for the displacement of boron atoms inside the iron lattice following the easiest crystallographic direction [001] for the diffusion pathway by minimizing the growth stresses [39]. Table 4 compares the experimental value of $\mathrm{Fe}_{2} \mathrm{~B}$ layer thickness measured on the cross-section of borided sample at $1123 \mathrm{~K}$ for $2.5 \mathrm{~h}$ with the predicted values of layer thickness by using the two kinetics approaches for an upper boron content of 9 wt. $\%$ in $\mathrm{Fe}_{2} \mathrm{~B}$. The diffusivity of boron in the iron phase was considered with the boron solubility within the matrix dependent upon the boriding temperature. For the alternative diffusion model, Equation (13) was used to determine the simulated value of $\mathrm{Fe}_{2} \mathrm{~B}$ layer thickness at $1123 \mathrm{~K}$ during $2.5 \mathrm{~h}$ corresponding to the incubation period of $1790 \mathrm{~s}$. For the integral method, a numerical resolution of the obtained DAE system was performed with the help of free software called Interactive Thermodynamics version 3.2. To solve such a system, the initial conditions should be consistent.

Tab. 4. Comparing the experimental $\mathrm{Fe}_{2} \mathrm{~B}$ layer thickness [25] with the values predicted by the two mathematical approaches for an upper boron concentration of 9 wt. $\%$ in $\mathrm{Fe}_{2} \mathrm{~B}$

\begin{tabular}{|c|c|c|}
\hline $\begin{array}{c}\text { Boriding } \\
\text { condition }\end{array}$ & $\begin{array}{c}\text { Experimental } \mathbf{F e}_{2} \mathbf{B} \\
\text { layer thickness }(\mu \mathrm{m})\end{array}$ & $\begin{array}{c}\text { Predicted values of } \\
\mathbf{F e}_{2} \mathbf{B} \text { layer thickness } \\
(\boldsymbol{\mu m})\end{array}$ \\
\hline & & $\begin{array}{c}45.41 \mu \mathrm{m} \\
\text { by the alternative } \\
\text { diffusion model }\end{array}$ \\
\cline { 3 - 3 } $\begin{array}{c}1123 \mathrm{~K} \text { for } \\
2.5 \mathrm{~h}\end{array}$ & $42.066 \pm 6.9947 \mu \mathrm{m}$ & $\begin{array}{c}45.56 \mu \mathrm{m} \\
\text { by the integral method } \\
\text { based on Equation }(28)\end{array}$ \\
\cline { 3 - 3 } & & $\begin{array}{c}45.54 \mu \mathrm{m} \\
\text { by the integral method } \\
\text { using the numerical } \\
\text { solution of DAE system }\end{array}$ \\
\hline
\end{tabular}

Hence, the initial layer thickness was set as $u_{0}=0.10 \mu \mathrm{m}$ with the respective values of $a_{0}$ and $b_{0}$ equal to 1.6840 and 0.15906 for an incubation period of $1790 \mathrm{~s}$ with the boron diffusivity in $\mathrm{Fe}_{2} \mathrm{~B}$ equal to $3.84 \times 10^{-12} \mathrm{~m}^{2} \mathrm{~s}^{-1}$ at $1123 \mathrm{~K}$. A very satisfactory concordance was obtained between the simulated values of layer thickness and the experimental result. As a limitation, both approaches disregarded the influence of carbon on the boronizing kinetics of ASTM A36 steel.

\section{CONCLUSIONS}

The following concluding points can be drawn from the present study:

- Two mathematical approaches were proposed aiming at investigating the growth kinetics of $\mathrm{Fe}_{2} \mathrm{~B}$ layer on ASTM A36 steel in the range of 1123 to $1273 \mathrm{~K}$.

- The first approach was based on the modified form of mass balance equation at the considered interface within an unsaturated matrix and for a constant boride incubation period. The second approach employed the integral method by considering the boron diffusivity in the iron phase.

- The estimated values of boron activation energies in ASTM A36 steel were very comparable for the two approaches $\left(=161.65 \mathrm{~kJ} \mathrm{~mol}^{-1}\right.$ for the alternative diffusion model and $160.96 \mathrm{~kJ} \mathrm{~mol}^{-1}$ for the integral method).

- The predicted values of $\mathrm{Fe}_{2} \mathrm{~B}$ layer thickness by the two approaches were in line with the experimental layer thickness obtained at $1123 \mathrm{~K}$ for $2.5 \mathrm{~h}$.

- For future studies, the alternative diffusion model can be applied to simulate the growth kinetics of $\mathrm{Fe}_{2} \mathrm{~B}$ layers on any steel substrate with the occurrence of boride incubation time.

\section{REFERENCES}

1. Kulka M. Trends in thermochemical techniques of boriding, in: Current Trends in Boriding, Engineering Materials. Springer: Cham, Switzerland, 2019.

2. Kulka M., Makuch N., Pertek A., Piasecki A. An alternative method of gas boriding applied to the formation of borocarburized layer, Materials Characterization 2012, 72, 59-67.

3. Küper A., Qiao X., Stock H.R., Mayr P. A novel approach to gas boronizing, Surface and Coatings Technology 2000, $130,87-94$.

4. Simonenko A.N., Shestakov V.A., Poboinya V.N. Liquid boriding in induction salt baths, Metal Science and Heat Treatment 1982, 24, 360-361.

5. Smol'nikov E.A., Sarmanova L.M. Study of the possibility of liquid boriding of high-speed steels, Metal Science and Heat Treatment 1982, 24,785-788. 
6. Campos I. , Oseguera J., Figueroa U., Garcia J.A., Bautista O., Kelemenis G. Kinetic study of boron diffusion in the paste-boriding process, Materials Science and Engineering A 2003, 352, 261-265.

7. Campos-Silva I., Ortíz-Domínguez M. Modelling the growth of $\mathrm{Fe}_{2} \mathrm{~B}$ layers obtained by the paste boriding process in AISI 1018 steel, Int. J. Microstructure and Materials Properties 2010, 5, 26-38.

8. Keddam M., Kulka M. The mean diffusion coefficient method for boriding kinetics of Armco iron, Metal Science and Heat treatment 2020, 62, 326-330.

9. Ipek M., Celebi Efe G., Ozbek I., Zeytin S, Bindal C. Investigation of Boronizing Kinetics of AISI 51100 Steel, Journal of Materials Engineering and Performance 2012 , 21, 733-738.

10. Kayali Y. Investigation of diffusion kinetics of borided AISI P20 steel in micro-wave furnace, Vacuum 2015, 121, 129-134.

11. Anthymidis K.G., Stergioudis E., Tsipas N. Boriding in a fluidized bed reactor, Materials Letters 2001, 51, 156-160.

12. Jiang Y., Bao Y., Wang M. Kinetic Analysis of Additive on Plasma Electrolytic Boriding, Coatings 2017, 61, 1-9.

13. Filep E., S. Farkas S. Kinetics of plasma-assisted boriding, Surface and Coatings Technology 2005, 199, 1-6.

14. Gunes I., Ulker S., Taktak S. Plasma paste boronizing of AISI 8620,52100 and 440C steels, Materials and Design 2011, 32, 2380-2386.

15. Jain V., Sundararajan G. Influence of the pack thickness of the boronizing mixture on the boriding of steel, Surface and Coatings Technology 2002, 149, 21-26.

16. Campos-Silva I., Ortiz-Domínguez M., VillaVelázquez C., Escobar R., López N. Growth Kinetics of Boride Layers: A Modified Approach, Defect and Diffusion Forum 2007, 272, 79-86.

17. Mebarek B., Keddam M. Fuzzy logic approach for modelling the formation of $\mathrm{Fe}_{2} \mathrm{~B}$ layer, International Journal of Computational Materials Science and Surface Engineering 2020, 9, 147-156.

18. Zuno-Silva J., Ortiz-Domínguez M., Keddam M., EliasEspinosa M., Damián-Mejía O., Cardoso-Legorreta E., Abreu-Quijano M. Boriding kinetics of $\mathrm{Fe}_{2} \mathrm{~B}$ layers formed on AISI 1045 steel, J. Min. Metall. Sect. B-Metall. 2014 , 50, 101-107.

19. Kouba R., Keddam M., Kulka M. Modelling of paste boriding process, Surface Engineering 2015, 31, 563-569.

20. Campos I., Islas M., Gonzalez E. , Ponce P., Ramírez G. Use of fuzzy logic for modeling the growth of $\mathrm{Fe}_{2} \mathrm{~B}$ boride layers during boronizing, Surface Coatings and Technology 2006, 201, 2717-2723.

21. Campos I., Bautista O., Ramírez G., Islas M., De La Parra J., Zúñiga L. Effect of boron paste thickness on the growth kinetics of $\mathrm{Fe}_{2} \mathrm{~B}$ boride layers during the boriding process, Applied Surface Science 2005, 243, 429-436.

22. Ramdan R.D., Takaki T., Tomita Y. Free Energy Problem for the Simulations of the Growth of Fe2B Phase Using Phase-Field Method, Materials Transactions 2008, 49, 2625-2631.

23. Keddam M., Jurči P. Analysis of boride layers' growth on AISI 316 steel by an alternative kinetic model, Metal Science and Heat Treatment (in print).
24. Mendoza C.I.V., Mendoza J.L.R., Galván V.I., Hodgkins R.P., Valdivieso A.L., Palacios L.L.S., Junquera V.I. Effect of substrate roughness, time and temperature on the processing of iron boride coatings: experimental and statistical approaches, International Journal of Surface Science and Engineering 2014, 8, 71-91.

25. Ortiz-Dominguez M., Gomez-Vargas O.A., Ares de Parga G., Torres-Santiago G., Velazquez-Mancilla R., Castellanos-Escamilla V.A., Mendoza-Camargo J., Trujillo-Sanchez R. Modeling of the Growth Kinetics of Boride Layers in Powder-Pack Borided ASTM A36 Steel Based on Two Different Approaches, Advances in Materials Science and Engineering 2019, Article ID 5985617.

26. Yu L.G., Chen X.J., Khor K.A., Sundararajan G. FeB/Fe ${ }_{2} B$ phase transformation during SPS pack-boriding: Boride layer growth kinetics, Acta Materialia 2005, 53, 2361-2368.

27. Nait Abdellah Z., Chegroune R., Keddam M., Bouarour B., Haddour L., Elias A. The Phase Stability in the Fe-B Binary System: Comparison between the Interstitial and Substitutional Models, Defect and Diffusion Forum 2012, $322,1-9$

28. Okamoto H. B-Fe (boron-iron), J. Phs. Eqil. and Diff. 2004, 25, 297-298.

29. Martini C., Palombarini G., Carbucicchio, M. Mechanism of thermochemical growth of iron borides on iron, Journal of Materials Science 2004, 39, 933-937.

30. Keddam M., Elias-Espinosa M., Ortiz-Domínguez M., Simón-Marmolejo I., Zuno-Silva J.: Pack-boriding of AISI P20 steel: Estimation of boron diffusion coefficients in the $\mathrm{Fe}_{2} \mathrm{~B}$ layers and tribological behaviour, International Journal of Surface Science and Engineering 2017, 11, 563-585.

31. Türkmen I., Yalamaç E., Keddam M. Investigation of tribological behaviour and diffusion model of $\mathrm{Fe}_{2} \mathrm{~B}$ layer formed by the pack-boriding process on SAE 1020 steel, Surface and Coatings Technology 2019, 377, 124888.

32. Türkmen İ., Yalamaç, E. Effect of Alternative Boronizing Mixtures on Boride Layer and Tribological Behaviour of Boronized SAE 1020 Steel, Met. Mater. Int. 2021. doi. org/10.1007/s12540-021-00987-8

33. Günen A., Karahan I.H., Karakaş M.S., Kurt B., Kanca Y., Çay V.V., Yıldız M. Properties and Corrosion Resistance of AISI H13 Hot-Work Tool Steel with Borided $\mathrm{B}_{4} \mathrm{C}$ Powders, Metals and Materials International 2020, 26, 1329-1340.

34. Keddam M., Chentouf S.M. A diffusion model for describing the bilayer growth $\left(\mathrm{FeB} / \mathrm{Fe}_{2} \mathrm{~B}\right)$ during the iron powderpack boriding, Applied Surface Science 2005, 252, 393-399.

35. Keddam, M., Kulka, M. Simulation of the Growth Kinetics of $\gamma^{\prime}$-Nitride Layers on Armco Iron by the Integral Method, Met. Sci. Heat Treat. 2020, 62, 529-533.

36. Goodman T.R. Application of Integral Methods to Transient Nonlinear Heat Transfer, Advances in Heat Transfer 1964,1, 51-122.

37. Press W.H., Flannery B.P., Teukolsky S.A. Numerical recipes in Pascal: the art of scientific computing. Cambridge University, 1989.

38. Ozbek I. Mechanical Properties and Kinetics of Borided AISI M50 Bearing Steel, Arabian Journal for Science and Engineering 2014, 39, 5185-5192.

39. C. Badini C., D. Mazza D. Preferred orientation of boride crystals in the borided layers: a quantitative method of evaluation, Journal of Materials Science 1988, 23, 3061-3066. 